\title{
Prognostic value of complementary biomarkers of neurodegeneration in a mixed memory clinic cohort
}

\author{
Mathias Holsey Gramkow ${ }^{\text {Corresp., }}{ }^{\text {, Le Gjerum }}{ }^{1}$, Juha Koikkalainen ${ }^{2}$, Jyrki Lötjönen ${ }^{2}$, Ian Law ${ }^{3}$, Steen Gregers \\ Hasselbalch $^{1}$, Gunhild Waldemar ${ }^{1}$, Kristian Steen Frederiksen ${ }^{1}$ \\ 1 Danish Dementia Research Centre, Department of Neurology, Rigshospitalet, University of Copenhagen, Copenhagen, Denmark \\ 2 Combinostics Ltd., Tampere, Finland \\ 3 Department of Clinical Physiology, Nuclear Medicine and PET, Rigshospitalet, University of Copenhagen, Copenhagen, Denmark \\ Corresponding Author: Mathias Holsey Gramkow \\ Email address: mathias.holsey.gramkow@regionh.dk
}

Background. Biomarkers of neurodegeneration, e.g. MRI brain atrophy and $\left[{ }^{18} \mathrm{~F}\right] \mathrm{FDG}-\mathrm{PET}$ hypometabolism, are often evaluated in patients suspected of neurodegenerative disease.

Objective. Our primary objective was to investigate prognostic properties of atrophy and hypometabolism.

Methods. From March 2015-June 2016, 149 patients referred to a university hospital memory clinic were included. The primary outcome was progression/stable disease course as assessed by a clinician at 12 months follow-up. Intracohort defined $z$-scores of baseline MRI automatic quantified volume and $\left[{ }^{18} \mathrm{~F}\right] \mathrm{FDG}$ -PET standardized uptake value ratios were calculated for all unilaterally defined brain lobes and dichotomized as pronounced atrophy $(+\mathrm{A}) /$ pronounced hypometabolism $(+\mathrm{H})$ at $z$-score $<0$. A logistic regression model with progression status as the outcome was carried out with number of lobes with the patterns $+\mathrm{A} /-\mathrm{H},-\mathrm{A} /+\mathrm{H},+\mathrm{A} /+\mathrm{H}$ respectively as predictors. The model was mutually adjusted along with adjustment for age and sex. A sensitivity analysis with a $z$-score dichotomization at -0.1 and -0.5 and dichotomization regarding number of lobes affected at 1 and 3 lobes was done.

Results. Median follow-up time was 420 days [IQR: 387-461 days] and 50 patients progressed. Patients with 2 or more lobes affected by the pattern $+\mathrm{A} /+\mathrm{H}$ compared to patients with $0-1$ lobes affected had a statistically significant increased risk of progression (odds ratio, $95 \%$ confidence interval: 4.33, 1.90-9.86) in a multivariable model. The model was partially robust to the applied sensitivity analysis.

Conclusion. Combined atrophy and hypometabolism as assessed by MRI and $\left[{ }^{18} \mathrm{~F}\right] \mathrm{FDG}$-PET in patients under suspicion of neurodegenerative disease predicts progression over 1 year. 


\section{Prognostic value of complementary biomarkers of 2 neurodegeneration in a mixed memory clinic cohort}

3

4

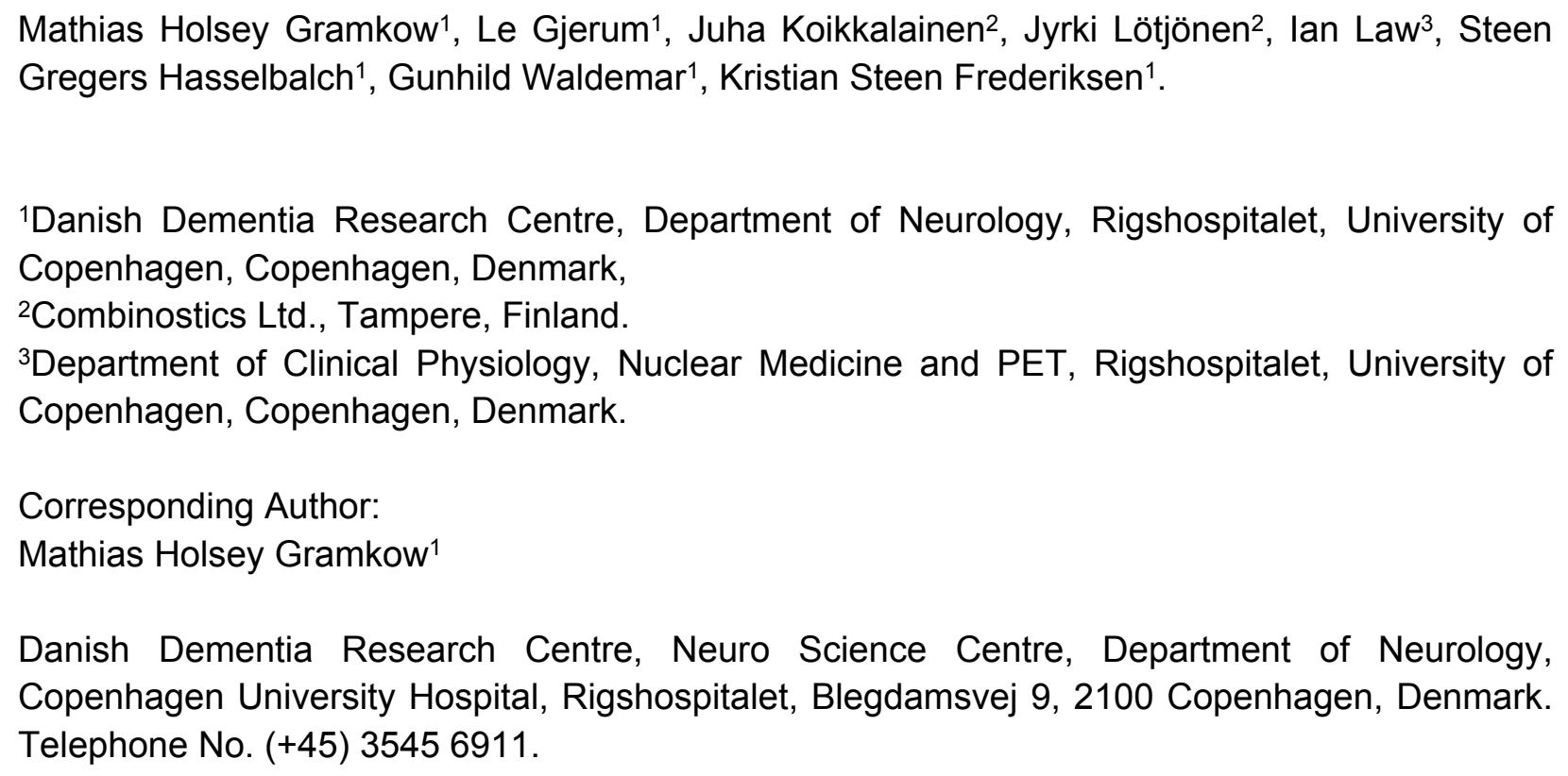
Copenhagen University Hospital, Rigshospitalet, Blegdamsvej 9, 2100 Copenhagen, Denmark. Telephone No. (+45) 35456911.

Email address: mathias.holsey.gramkow@regionh.dk.

1 
44

45

46

47

48

49

50

51

52

53

54

55

56

57

58

59

60

61

62

63

64

65

66

67

68

69

70

71

72

73

74

75

76

77

78

79

80

81

\section{Abstract}

Background. Biomarkers of neurodegeneration, e.g. MRI brain atrophy and [ $\left.{ }^{18} \mathrm{~F}\right] \mathrm{FDG}-$ PET hypometabolism, are often evaluated in patients suspected of neurodegenerative disease. Objective. Our primary objective was to investigate prognostic properties of atrophy and hypometabolism.

Methods. From March 2015-June 2016, 149 patients referred to a university hospital memory clinic were included. The primary outcome was progression/stable disease course as assessed by a clinician at 12 months follow-up. Intracohort defined z-scores of baseline MRI automatic quantified volume and $\left[{ }^{18} \mathrm{~F}\right] \mathrm{FDG}-\mathrm{PET}$ standardized uptake value ratios were calculated for all unilaterally defined brain lobes and dichotomized as pronounced atrophy $(+A) /$ pronounced hypometabolism $(+H)$ at $z$-score $<0$. A logistic regression model with progression status as the outcome was carried out with number of lobes with the patterns $+\mathrm{A} /-\mathrm{H},-\mathrm{A} /+\mathrm{H},+\mathrm{A} /+\mathrm{H}$ respectively as predictors. The model was mutually adjusted along with adjustment for age and sex. A sensitivity analysis with a z-score dichotomization at -0.1 and -0.5 and dichotomization regarding number of lobes affected at 1 and 3 lobes was done.

Results. Median follow-up time was 420 days [IQR: 387-461 days] and 50 patients progressed. Patients with 2 or more lobes affected by the pattern $+\mathrm{A} /+\mathrm{H}$ compared to patients with 0-1 lobes affected had a statistically significant increased risk of progression (odds ratio, $95 \%$ confidence interval: 4.33, 1.90-9.86) in a multivariable model. The model was partially robust to the applied sensitivity analysis.

Conclusion. Combined atrophy and hypometabolism as assessed by MRI and $\left[{ }^{18} \mathrm{~F}\right] \mathrm{FDG}-\mathrm{PET}$ in patients under suspicion of neurodegenerative disease predicts progression over 1 year. 


\section{Introduction}

83

84

85

86

87

88

89

90

91

92

93

94

95

96

97

98

99

100

101

102

103

104

105

106

107

108

109

110

111

112

113

114

115

116

117

118

119

120

121

122

123

124
Dementia is a substantial health problem worldwide as disease incidence increases with advancing age and the global older generation is growing with an increasing rate according to the UN World Population Prospect from 2019. Forty-seven million patients were estimated to live with dementia in 2015 and it is forecast that dementia will affect 132 million individuals by 2050 (Geneva: World Health \& Organization, 2017). Neurodegeneration is a disease state defined by progressive loss of neuronal function and structure (Spillantini \& Goedert, 2013). Many dementia disorders, the most prominent being Alzheimer's disease (AD), frontotemporal dementia and dementia with Lewy bodies, share this neuropathological property (Prince et al., 2013; Masters et al., 2015; Mueller et al., 2017; Nestor, 2017).

Use of biomarkers reflecting neurodegeneration may be a part of the clinical work-up when evaluating patients suspected of cognitive impairment (Albert et al., 2011). Apart from helping to establish the diagnosis, neurodegenerative biomarkers may predict disease course. Established biomarkers of neurodegenerative diseases are tau protein measured in the cerebrospinal fluid (CSF), brain atrophy assessed by MRI and 2-[18 F]fluoro-2-deoxy-D-glucose $\left(\left[{ }^{18} \mathrm{~F}\right] \mathrm{FDG}\right)$ PET assessment of brain hypometabolism (Jack et al., 2013). While prognostic properties of single markers have previously been evaluated (Chetelat et al., 2005; Perani et al., 2016; Ottoy et al., 2019), the combination of markers has not been tested extensively. Since two or more biomarkers are often available to the clinician for the same patient, performance of combined biomarkers may be more useful and represents a more clinically oriented way of viewing biomarkers. Physicians are often faced with conflicting results when looking at a plethora of markers. This makes interpretation in clinical practice difficult with regards to diagnosis but also when assessing risk for progression (McKhann et al., 2011), and validated biomarkers of progression are effectively not available to clinicians (McGhee et al., 2014). Moreover, while $\mathrm{MRI}$ and $\left[{ }^{18} \mathrm{~F}\right] \mathrm{FDG}-\mathrm{PET}$ are measures of different aspects in the neurodegenerative process, they nevertheless are markers of the same process. Therefore, it remains undetermined whether the 2 modalities hold complementary or additive information with regards to risk of progression.

An evaluation and classification of the existing biomarkers of neurodegeneration in order to identify the most appropriate markers to predict progression will aid the clinicians to initiate relevant care and recognize potential patients for early therapeutic intervention. In addition to this, patients may wish to know the likely course of their disease, including risk of progression, in order to plan for the future. This study will evaluate MRI brain atrophy, $\left[{ }^{18} \mathrm{~F}\right] \mathrm{FDG}-\mathrm{PET}$ and CSF-total-tau and their usefulness in assessing risk of clinical progression in patients referred to a memory clinic under suspicion of neurodegenerative disease. We hypothesized that brain atrophy, hypometabolism and high CSF-total tau were associated with clinical progression in patients suspected of neurodegenerative disease. Secondly, we hypothesized that there was congruency between biomarkers of neurodegeneration with regards to progression. 
125

126

127

128

129

130

131

132

133

134

135

136

137

138

139

140

141

142

143

144

145

146

147

148

149

150

151

152

153

154

155

156

157

158

159

160

161

162

163

164

\section{Materials \& Methods}

\section{Participants, study protocol and ethical statement}

A total of 149 patients referred to the Memory clinic at Rigshospitalet $(\mathrm{RH})$ in Copenhagen, Denmark suspected of neurodegenerative disease were included in the present study. The cohort was part of a larger EU-supported study, PredictND, which investigated the clinical impact of a computer assisted decision support tool in diagnosis and prognosis of patients referred to memory clinics with suspicion of neurodegenerative disease. The original study recruited 208 patients at $\mathrm{RH}$. The study details of PredictND are reported elsewhere (Bruun et al., 2019). In short, the inclusion criteria for the PredictND study were 1) patients suspected of having cognitive complaints as a result of subjective cognitive decline (SCD), mild cognitive impairment $(\mathrm{MCl})$ or dementia 2) a Mini-Mental State Examination (MMSE) $\geq 18$ and a T1-weighted MRI ( $\geq 1.5$ Tesla) available. Exclusion criteria were major psychiatric disorder, excessive alcohol intake or substance abuse within the last two years and other brain disorders that could explain the cognitive complaints. Inclusion criteria for the present study were 1) recruited at RH 2) a brain MRI at baseline including a T1-weighted MR image with slice thickness $<2 \mathrm{~mm}$ of sufficient quality for analysis, 3) $\left[{ }^{18} \mathrm{~F}\right] \mathrm{FDG}-\mathrm{PET}$ at baseline, 4) at least 12-months follow-up. Patients in the PredictND study were evaluated at a consensus conference held for specialist physicians, nurses and neuropsychologist at the respective clinics and a diagnosis was given, the criteria for which are described elsewhere (Bruun et al., 2019). The PredictND study was approved by the Scientific Ethics Committee of the Capital Region of Denmark (H-1-2014-126) and study experiments were carried out in accordance with the Helsinki Declaration. All patients provided written informed consent for their data to be used for research purposes.

\section{Outcome assessment}

The primary outcome for the present study was progression assessed at a follow-up clinical evaluation 12 months post-diagnosis. The 12-month follow-up clinical evaluation was done by an experienced dementia specialist, however not necessarily the same clinician who did the initial consultation. At the follow-up visit, where the patient was evaluated with at least a Mini Mental State Examination (MMSE) (Folstein, Folstein \& McHugh, 1975) and a Clinical Dementia Rating (Hughes et al., 1982), the disease course was determined as either progression, fluctuation, stable and improvement. Baseline scans and results of the CSF analysis were not included in the assessment of disease course at 12-month follow-up, although the clinician was not blinded to diagnostic test data. In the present study, the disease course categories fluctuation, improvement and stable were collapsed into a single category called stable, as too few patients' disease courses were categorized as fluctuation (one patient) or improvement (five patients) for a meaningful analysis to be undertaken. 
MRI

168

Scans were acquired using a T1-weighted gradient echo sequence on 3 Tesla scanners. Automated image quantification analysis was done in the PredictND tool as described by Koikkalainen et al (Koikkalainen et al., 2016). In short, 3-D images were segmented using a multi-atlas segmentation approach to 139 regions. Regions of interest (ROIs) for individual bilaterally defined brain lobes (occipital, temporal, frontal and parietal) and a total ventricular volume were constructed from this initial segmentation of structures listed under Supplemental Table S1. The total ventricular volume was chosen as a possible prognostic marker, as it had shown promise within AD (McGhee et al., 2014).

176 scanners according to international practice guidelines (Varrone et al., 2009). An in-house developed software tool was used for the data analysis of images. Images were coregistered to their corresponding segmented MR images to generate corresponding ROIs as described under MRI, and an ROI of total grey and white matter uptake was defined. Standardized uptake value ratios (SUVRs) for ROls were referenced to the mean activity in the white matter of the cerebellum.

\section{CSF-total tau}

CSF was collected by lumbar puncture at the baseline visit and handled according to standard operating procedures. CSF-total tau was measured using a commercially available enzyme-linked immunosorbent assay (Innotest, Fujirebio, Ghent, Belgium). In total, 76 patients had CSF-total tau measured.

191

192

193

194

195

196

\section{Statistical analysis}

Spearman's $\rho$ was calculated for baseline variables of interest. Median follow-up time was defined as days from baseline visit till follow-up visit. Z-scores for the biomarkers MRI-total ventricular volume, $\left[{ }^{18} \mathrm{~F}\right]$ FDG -PET-total grey and white matter SUVRs and CSF-total tau were calculated using the intracohort mean and standard deviation for each variable. Variables were dichotomized and categorized as abnormal if the z-score was higher (MRI-total ventricular volume and CSF-total tau) or lower ([18F]FDG -PETtotal grey and white matter SUVRs) than zero. The number of abnormal markers were used as a predictor in a multivariable logistic regression model (M1) with progression

201

202 status (progressed/stable) at follow-up as the outcome. Interval validation was done in the form of 10-fold 1000 times cross validation using the caret package in $\mathrm{R}$ and balanced accuracy for the model was calculated. Z-scores were calculated in the same way for the MRI intralobal volumes and [18F]FDG -PET SUVRs for each unilaterally 
205

206

207

208

209

210

211

212

213

214

215

216

217

218

219

220

221

222

223

224

225

226

227

228

229

230

231

232

233

234

235

236

237

238

239

240

241

242

243

244

\section{8}

40

defined lobe (left and right frontal, parietal, occipital and temporal). Dichotomization for these variables were done at a $z$-score $=0$ and each lobe was defined with the labels pronounced atrophy (z-score for MRI volume $<0$ ) or unpronounced atrophy (z-score for MRI volume $>0$ ) and concurrently pronounced hypometabolism (z-score for $\left[{ }^{18} \mathrm{~F}\right] \mathrm{FDG}$ PET SUVR < $)$ ) or unpronounced hypometabolism (z-score for [ $\left.{ }^{18} \mathrm{~F}\right] \mathrm{FDG}-\mathrm{PET}$ SUVR > $0)$. An atrophy/hypometabolism pattern for each lobe was defined by either pronounced atrophy $(+A)$ or unpronounced atrophy $(-A)$, and pronounced hypometabolism $(+\mathrm{H})$ or unpronounced hypometabolism $(-\mathrm{H})$. Three variables, each counting the number of lobes with the patterns $+\mathrm{A} /-\mathrm{H},-\mathrm{A} /+\mathrm{H}$ and $+\mathrm{A} /+\mathrm{H}$ respectively were then entered as separate dichotomous predictors in a multivariable logistic regression model (M2) with the same outcome and adjustment as in M1 as well as mutual adjustment. Lastly, anatomical variables were constructed with levels explained and illustrated in Supplemental Figure S1. Shortly, levels for each lobe (left and right lobe taken as a whole) were defined as 1 ) isolated atrophy, 2) isolated hypometabolism, 3) congruent atrophy and hypometabolism and non-isolated atrophy or hypometabolism 4) no abnormality. Anatomical variables were added as predictors in M2 in an exploratory model (M3) and mutually adjusted for in a multivariable model. Multicollinearity in M3 was tested for by eigensystem analysis. Sensitivity analyses, investigating dichotomization at a z-score of 0.1 and 0.5 (MRI-total ventricular volume and CSF-total tau) and at -0.1 and $-0.5\left(\left[{ }^{18} \mathrm{~F}\right] \mathrm{FDG}-\mathrm{PET}\right.$-total grey and white matter SUVRs, pronounced/unpronounced atrophy and pronounced/unpronounced hypometabolism), were carried out in M1 and M2. Furthermore, a sensitivity analysis was carried out in M2 with dichotomization at 1 lobe affected and 3 lobes affected by specific patterns. The same models were run (M2 and M3) as pre-planned analyses in a sub-cohort of patients with $\mathrm{MCl}$ and dementia. Linear regression was done for predictors in $\mathrm{M} 1$ against MMSE total score follow-up score subtracted from baseline and linear regression model assumptions were checked by visual inspection of $Q-Q$ and residuals plots. For all constructed logistic regression models, odds ratios (ORs) and $95 \%$ confidence intervals (95\% Cls) were calculated using the finalfit package. Only twosided tests were used and a significance level of 0.05 was imposed. All statistical analyses were carried out in R (3.2.3) ("R Core Team, R: A Language and Environment for Statistical Computing," 2016). 


\section{Results}

246

247 The baseline characteristics of patients included in the present study are presented in

248 Table 1. The mean age was 70.3 years (SD 9.8) and males and females were near

249 equally represented in the material. Patients' median MMSE total score was 28 (range

250 18-30). Median follow-up time was 420 days [IQR: 387-461 days] and at follow-up 50

251 patients had progressed. Figure 1 shows the Spearman correlations between variables

252 of interest. MRI total ventricular volume correlated negatively with total grey and white

253 matter uptake $\left[{ }^{18} \mathrm{~F}\right] \mathrm{FDG}-\mathrm{PET}$ with $(\rho=-0.25)$ and positively with age $(\rho=0.38)$. MMSE

254 total score correlated positively with [ $\left.{ }^{18} \mathrm{~F}\right] \mathrm{FDG}-\mathrm{PET}$ total grey and white matter uptake

$255(\rho=0.31)$ and negatively with CSF-total tau $(\rho=-0.28)$. All other correlations were not

256 significant ( $\rho$ not shown). Linear regression of each biomarker of neurodegeneration

257 (MRI-total ventricular volume, [ $\left.{ }^{18} \mathrm{~F}\right] \mathrm{FDG}$-PET total grey and white matter uptake and

258 CSF-total tau) against the MMSE score difference between follow-up and baseline are 259 shown in the Supplemental Figures S2-S4. In these models, [ $\left.{ }^{18} \mathrm{~F}\right] \mathrm{FDG}$-PET total grey

260 and white matter uptake associated positively with the MMSE change from baseline to 261 follow-up $\left(r^{2}=0.039, p=0.017\right)$.

262

\section{Abnormal markers of neurodegeneration and progression}

Table 2 gives the results of a logistic regression analysis with biomarkers of neurodegeneration (MRI total ventricular volume, $\left[{ }^{18} \mathrm{~F}\right] \mathrm{FDG}-\mathrm{PET}$ total grey and white matter uptake and CSF-total tau) as predictors of progression at follow-up. The results of Model 1 (Table 2) showed that with each additional abnormal marker the risk of progression increased when tested against zero abnormal markers (1 abnormal marker: OR 2.38, 95 \% Cl 0.59-9.66, 2 abnormal markers: OR 2.40, $95 \% \mathrm{Cl} 0.59-9.71$, and 3 abnormal markers: OR 3.66, $95 \% \mathrm{Cl} 0.51-26.36$, in the multivariable model). Model 1 had an accuracy of 0.59 in a 10-fold 1000 times cross-validation and a balanced accuracy of 0.53 in a simple prediction of progression within the dataset. Directionality of point estimates were only partially robust to sensitivity analyses (Supplemental Table S2). Model 2 (Table 2) did not include CSF-total tau as a predictor but was otherwise identical to Model 1. The results of Model 2 showed that with each additional abnormal marker the risk of progression increased when tested against zero abnormal markers (1 abnormal marker: OR 2.68, $95 \% \mathrm{Cl} 1.01-7.12$ and 2 abnormal markers: OR 3.45, $95 \%$ $\mathrm{Cl} 1.16-10.28$, in the multivariable model). Model 2 had an accuracy of 0.63 in a 10 -fold 1000 times cross-validation and a balanced accuracy of 0.58 . Directionality and $95 \%$ Cls for point estimates were robust to a $z$-score dichotomization at $-0.1 / 0.1$, but not at 0.5/0.5 (Supplemental Table S2).

\section{Atrophy and hypometabolism patterns and progression}


284 Table 3 gives the results of a logistic regression analysis investigating variables

285

286

287

288

289

290

291

292

293

294

295

296

297

298

299

300

301

302

303

304

305

306

307

308

309

310

311

312

313

314

315

316

317

318

319

320

321

322

323

expressing different patterns of atrophy $(+A)$ and hypometabolism $(+H)$ as predictors of progression. Comparing patients who had two or more lobes affected by the pattern $+\mathrm{A}$ and $+\mathrm{H}$ with patients who had $0-1$ affected lobes resulted in an OR of $4.46(95 \% \mathrm{Cl}$ 2.16-9.22) in the univariable model, and an OR of 4.33 (95\% Cl 1.90-9.86) in the multivariable model. This indicated an overall four-fold increase in the odds of 1-year progression, which reached statistical significance $(p<0.001)$. The directionality and statistical significance of this point estimate was robust to a sensitivity analysis investigating a dichotomization at a $z$-score value of -0.1 . The same was true when investigating a dichotomization at 1 or more affected lobes and 3 or more affected lobes with a z-score dichotomization kept at 0 , meaning that an increased risk of progression was observed for patients with 1 or more and 3 or more lobes affected using the same comparison as above. A sensitivity analysis investigating a z-score dichotomization at 0.5 showed a preservation of directionality, although statistical significance was not reached for the multivariable estimate (Supplemental Table S2).

To explore our chosen outcome of physician's assessment's validity, we also evaluated a model using the outcome of a decline of 3 or more points on the MMSE scale as an indication of progression (see Supplemental Table S3A), which did not change the results remarkably of the model presented in Table 3. We also explored the influence of disease duration and educational level of the participants as possible confounders in an additional model (see Supplemental Table S3B), where we included these variables to the model presented in Table 3. This analysis showed no discernible influence on the results obtained.

A pre-planned subgroup analysis with parameters identical to the model pertaining to the results reported in Table 3 was carried out in patients diagnosed with $\mathrm{MCl}$ or dementia, thus excluding patients with SCD (Supplemental Table S4). We found that having 2 or more lobes affected by the pattern $+\mathrm{A}$ and $+\mathrm{H}$ was associated with an increased probability of progression (univariable: OR 2.82, $95 \% \mathrm{Cl} 1.31-6.10$; multivariable: OR 2.91, $95 \% \mathrm{Cl} 1.22-6.97)$.

\section{Anatomical variation of atrophy and hypometabolism patterns and progression}

Table 4 gives the results of an exploratory logistic regression analysis investigating anatomical variation in patterns of atrophy and hypometabolism as predictors of progression (For detailed illustration of the construction of variables see Supplemental Figure S4). The results of the multivariable analysis showed that the presence of intralobal congruent atrophy and hypometabolism and/or the presence of atrophy/hypometabolism that was not isolated in the occipital lobe was associated with a lower probability of progression compared to having no abnormality (OR 0.06, $95 \%$ $\mathrm{Cl} 0.01-0.46$ ). Eigensystem analysis resulted in a condition number of 10.3 , indicating little or no concern of multicollinearity in this model. 
324 A pre-planned subgroup analysis with parameters identical to the model reported in 325 Table 4 was carried out in patients diagnosed with $\mathrm{MCl}$ or dementia, thus excluding 326 patients with SCD. The results of this analysis are shown in Supplemental Table S5.

327 The results of this multivariable analysis showed that the presence of intralobal 328 congruent atrophy and hypometabolism and/or non-isolated atrophy/hypometabolism in 329 the occipital lobe was associated with a lower probability of progression compared to 330 having no abnormality (OR $0.16,95 \% \mathrm{Cl} 0.02-1.37$ ), but the estimate did not reach 331 statistical significance $(p=0.094)$.

332

333

334

335

336

337

338

339

340

341

342

343

344

345

346

347

348

349

350

351

352

353

354

355

356

357

358

359

360

361

362

363 
364

365

366

367

368

369

370

371

372

373

374

375

376

377

378

379

380

381

382

383

384

385

386

387

388

389

390

391

392

393

394

395

396

397

398

399

400

401

402

403

\section{Discussion}

In the present study we investigated the ability of 3 different measures of neurodegeneration to predict the disease course after 1 year in patients suspected of neurodegenerative disease. Evidence of neurodegeneration on both MRI and [ $\left.{ }^{18} \mathrm{~F}\right] \mathrm{FDG}$ -PET in 2 or more lobes compared to having 0-1 lobes affected was associated with a more than fourfold increase in odds of progression after 1 year. Patients with isolated atrophy or hypometabolism-dominated patterns were not at an increased risk of progression after 1 year. These estimates were validated in sensitivity analyses and further confirmed by subgroup analysis of patients with $\mathrm{MCl}$ and dementia. The findings indicate that MRI and [ $\left.{ }^{18} \mathrm{~F}\right] \mathrm{FDG}$-PET holds complementary information which may reflect different aspects of neurodegeneration. To our knowledge, this study is the first to report on the prognostic properties of combined MRI and [ $\left.{ }^{18} \mathrm{~F}\right] \mathrm{FDG}-\mathrm{PET}$ quantitative data within a mixed memory clinic cohort.

While we acknowledge that several studies have investigated the relationship between biomarkers of neurodegeneration and progression, most have been conducted in patients with $\mathrm{MCl}$ (Chetelat et al., 2005; Fellgiebel et al., 2007; Landau et al., 2010;

Dickerson \& Wolk, 2013; Bouallègue, Mariano-Goulart \& Payoux, 2017; Altomare et al., 2019), or AD (Kester et al., 2009; Ottoy et al., 2019). However, it seems reasonable that biomarkers of neurodegeneration could be used as prognostic tools in all diseases that have neurodegeneration as a prime component of brain pathology. Thus, if a patient is under suspicion of a neurodegenerative disease, regardless of the disease suspected, there seems to be prognostic value in both MRI and [ $\left.{ }^{18} \mathrm{~F}\right] \mathrm{FDG}-\mathrm{PET}$ quantitative data. Our results are in line with previous findings with regards to the prognostic properties of MRI (Dickerson \& Wolk, 2013) and [ ${ }^{18}$ F]FDG -PET (Mielke et al., 1994; Fellgiebel et al., 2007; Walhovd et al., 2010a), although the cohorts in the aforementioned studies differ markedly from ours, as we also included patients with a non-AD dementia and patients with SCD. By doing so, our findings are generalizable to the typical array of patients seen for initial evaluation in a memory clinic. On the other hand, our prognostic markers may also simply be identifying patients with SCD versus patients with $\mathrm{MCI}$ or dementia. To overcome the issue of whether our markers were mainly diagnostic or prognostic (i.e. determines the diagnostic categories of $\mathrm{MCl}$ and dementia against SCD), we further validated our findings by excluding patients with SCD in a pre-planned analysis and this confirmed our initial results, although we did not attempt to replicate the results in the dementia group only. In analyzing data from this study, we aimed to mimic the clinical approach, with regards to how clinicians may use imaging data, when defining our variables of interest. Investigating larger brain structures such as brain lobes in a 
404 quantitative manner might seem more in tune with everyday clinical practice, although

405 not a perfect mimic of it, where the $\left[{ }^{18} \mathrm{~F}\right] \mathrm{FDG}-\mathrm{PET}$ images are visually inspected

406 (Shivamurthy et al., 2015; Gallivanone, Della Rosa \& Castiglioni, 2016; Kato et al., 407 2016) and thus less emphasis is put on smaller abnormalities, which might drown in 408 unspecific changes. This is in contrast to most other studies investigating [ $\left.{ }^{18} \mathrm{~F}\right] \mathrm{FDG}$-PET 409 in a prognostic setting, where smaller (Walhovd et al., 2010b), sometimes unilaterally 410 defined ROls (Chetelat et al., 2005) seem to be the preference. As such, our results 411 show that either MRI or [ $\left.{ }^{18} \mathrm{~F}\right] \mathrm{FDG}-\mathrm{PET}$ quantitative data with our pre-processing 412 pipeline might have limited prognostic information, but the combination of markers 413 seems to improve the prognostic precision as the markers might highlight different 414 areas of disease pathology, which is also confirmed by studies in AD (Walhovd et al., 415 2010a).

416 Our model incorporating CSF-total tau could not reliably predict progression, which is in 417 line with other findings (McGhee et al., 2014). This could be attributed to the limited 418 number of patients who had CSF-total tau measured. This impaired the statistical 419 power, as the directionality of the point estimates for an increasing number of abnormal markers showed. In a review by McGhee et al (McGhee et al., 2014) which looked at disease progression markers in $A D$, the prognostic value of CSF-total tau was small and seemed hard to capture, even in studies including 100 (Zetterberg et al., 2006) and 274 (Andreasen et al., 1999) patients. Thus, CSF-total tau when measured alone might not contribute in a meaningful manner to assessment of risk of progression but there may be confounding factors limiting the usability of the marker which cannot be adequately accounted for. One aspect that could confound results pertaining to not just tau but possibly any CSF marker, is the blood-brain barrier (BBB) permeability. Studies investigating a surrogate marker of BBB permeability, namely CSF/serum albumin ratio, have shown in Parkinson's disease (Liguori et al., 2017), that this ratio increases with disease severity along with amyloid beta $(A \beta)$ and total tau. Adjusting for this ratio may better elucidate the prognostic value of tau, although conclusions on this matter are merely speculative at this point, as a better understanding of the CSF fluid dynamics and physiology is needed. Also, it has been shown that when combining tau with an $A D$ marker such as $A \beta(1-42)$, cognitive decline can be predicted (Hansson et al., 2018), meaning that ratios might be better at predicting progression, although the biological reasoning behind and interpretation of these ratios need to be defined more clearly. Recent studies done using data from the Alzheimer's Disease Neuroimaging Initiative have shown that an increase in CSF-phosphorylated-tau, which is an AD-specific CSF marker, may precede tau-PET positivity (Meyer et al., 2020), meaning that an increase in CSF-total-tau could be indicative of early stage disease and thus the risk of progression is lower when only this marker is abnormal.

In a model excluding CSF-total tau as a predictor, we evaluated the prognostic value of a proposed marker of disease progression in $A D$, namely MRI total ventricular volume. 
444 We showed that patients who had either an abnormal value for this marker or $\left[{ }^{18} \mathrm{~F}\right] \mathrm{FDG}$ 445 PET or both were at an increased risk of progression, thus confirming in part earlier 446 studies (Nestor et al., 2008; Vemuri et al., 2010), although the cohorts studied differed.

447 This indicates that this marker might hold prognostic value in a mixed memory clinic 448 cohort. In contrast to this finding, we could not show a statistically significant 449 relationship between total ventricular volume and MMSE change in linear regression 450 models. This may reflect the fact the MMSE perhaps does not capture all aspects of disease progression as viewed by the clinician or simply that MRI ventricular volume cannot stand alone as a prognostic marker.

In an exploratory model we investigated whether the exact lobe-wise anatomical localization of atrophy and/or hypometabolism had an influence on the risk of progression. We found that having intralobal congruent atrophy and hypometabolism and/or non-isolated atrophy/hypometabolism in the occipital lobe was associated with a lower probability of progression compared to having no abnormality. Further, we addressed the concern of multicollinearity by eigensystem analysis. These results could not be replicated in a subgroup of patients with $\mathrm{MCl}$ and dementia. This relationship only revealed itself in the multivariable analysis, meaning that the univariable estimate was confounded by other included variables. This would suggest that a subset of patients, maybe especially those with occipital lobe restricted atrophy/hypometabolism somehow deviated in terms of non-occipital neurodegeneration and progression. Our interpretation is that the seemingly protective effect of having atrophy and/or hypometabolism in the occipital lobe is a sign of non-neurodegenerative disease, since the occipital lobe is often spared in neurodegenerative dementias (Harper et al., 2017). Patients with isolated occipital atrophy may have a non-neurodegenerative disease (e.g. alcohol related dementia) which may be more stable. Another explanation as to why we see this particular protective effect is that patients are asked to close their eyes during the acquisition of the $\left[{ }^{18} \mathrm{~F}\right] \mathrm{FDG}-\mathrm{PET}$ scan, meaning that if patients are unable to cooperate fully, maybe due to their neurodegenerative disease, this might show up as increased metabolism in the occipital lobe due to visual stimulation. However, the protective effect of this specific pattern also raises the concern of the validity of the model, and this concern was corroborated by the missing ability to replicate results in subgroup-analyses.

The strengths of this study are the well-described cohort, the clinically defined outcome, and the resemblance of both the cohort and our chosen measures of

neurodegeneration to the clinic. This means, that our findings could be generalizable to a broad range of memory clinic patients that want to know their prognosis. Another strength is our clinically-driven hypothesis generation, by which we aimed to emulate the process of visual inspection of MRI and [ $\left.{ }^{18} \mathrm{~F}\right] \mathrm{FDG}-\mathrm{PET}$ scans a memory clinic physician carries out in clinical practice. Further, this enabled us to convert the images into quantitative data that can be assessed in a statistical manner. 
484 We acknowledge inherent limitations of this study. First and foremost, we chose a 485 pragmatic approach to defining clinical progression. A physician who in most cases 486 knew the patient was given four options of describing the disease course since the 487 diagnosis as perceived by the physician herself, the patient and the caregiver. This non488 validated measure of assessing clinical progression might impose bias. We investigated 489 whether a model with MMSE decline of 3 points or more would change the results of our 490 main finding, which it did not, indicating that both measures hold value in assessing progression. A critique of our study could also be that our cohort is too broadly defined and that we did not examine the prognostic value within the etiological diagnoses. On the other hand, markers of neurodegeneration should have usefulness in all neurodegenerative diseases and a relatively high number of patients in clinical practice do not receive a specific etiological diagnosis either because it may not be ascertainable or due to limited resources within centers (Amjad et al., 2018). We tried to accommodate this view by choosing larger ROIs that reflect a more general approach to the pathological patterns of neurodegenerative disease, although this limited sensitivity. We are aware of the fact that simply defining atrophy and hypometabolism as presented here done does not necessarily mean that actual atrophy and hypometabolism was present, although it is reasonable to suggest that a large proportion of the studied population indeed have substantial atrophy and hypometabolism due to the diagnoses they eventually received. Nonetheless, this presents a risk of oversimplification. Also, although we employed internal validation to test the robustness of our results, the gold standard of biomarker studies demands external validation of the model in an independent cohort. This was not done and presents a drawback. No control sample was included in the main study, which is why we resort to an intracohort-defined zscore. The inclusion of a control sample could have improved the validity of the results, although the selection process associated with inclusion of control samples can suffer from the causes of selection bias and may give false positive findings. We did not consider vascular damage nor did we make amends to filter out the possible effect of vascular damage from our subjects. We believe that this is an area of research that deserves attention, but we also found it to be beyond the scope of this work to account for, as we mainly study the downstream cascades of neurodegeneration and vascular damage can be thought of as an up-stream event. We also did not study the comparison of a clinical progression risk rated at baseline with our method and further, we did not adjust for intracranial volume which could confound our results, although an

518 adjustment for sex accounts for some of this variation. Further, generalization is limited 519 to patients with a MMSE $\geq 18$.

520 A perspective to be added to this study is the relatively new idea of a pre- and post521 biomarker counseling effort (Herukka et al., 2017), which is applicable for patients 522 diagnosed with $\mathrm{MCl}$. Biomarker counseling should be given as continuous support also 523 after the patient is informed of a positive CSF biomarker result ensuring that the patient 
524 is cared for in a way that fits the possibly dire outcome. The results of the present study 525 support the notion that biomarkers indeed hold promise as prognostic markers, but we

526 need to care for and instruct patients that receive such a prognosis in a meaningful, 527 empathetic way, ensuring that patients know what to do to stay healthy for as long as 528 possible. Further, it seems that hypometabolism should also be considered when 529 inspecting a $\left[{ }^{18} \mathrm{~F}\right] \mathrm{FDG}-\mathrm{PET}$ scan even if the MRI shows atrophy, meaning that there 530 probably is excess hypometabolism that is missed when simply ascribing any and all 531 hypometabolism to atrophy.

532

533

\section{Conclusions}

534

535 In conclusion, the present findings expand the knowledge on the usefulness of 536 biomarkers of neurodegeneration in the clinical setting. Complementary markers of 537 neurodegeneration add to the prognostic value of the isolated biomarkers. However, 538 these were preliminary findings which need further validation. Future studies with larger

539 cohorts should be conducted in this area to validate our findings and to further elucidate 540 the prognostic value of these biomarkers of neurodegeneration.

541

542

\section{Acknowledgements}

543

544

545

We would like to extend our thanks to all patients for their willingness to participate in this study.

546

547

548

549

550

551

552

553

554

555

556

557

558

559

560

561

562

563 
564

565

566

567

568

569

570

571

572

573

574

575

576

577

578

579

580

581

582

583

584

585

586

587

588

589

590

591

592

593

594

595

596

597

598

599

600

601

602

603

604

605

606

607

608

609

\section{References}

Albert MS, DeKosky ST, Dickson D, Dubois B, Feldman HH, Fox NC, Gamst A, Holtzman DM, Jagust WJ, Petersen RC, Snyder PJ, Carrillo MC, Thies B, Phelps $\mathrm{CH}$. 2011. The diagnosis of mild cognitive impairment due to Alzheimer's disease: recommendations from the National Institute on Aging-Alzheimer's Association workgroups on diagnostic guidelines for Alzheimer's disease. Alzheimer's \& dementia : the journal of the Alzheimer's Association 7:270-9. DOI: 10.1016/j.jalz.2011.03.008.

Altomare D, Ferrari C, Caroli A, Galluzzi S, Prestia A, van der Flier WM, Ossenkoppele R, Van Berckel B, Barkhof F, Teunissen CE, Wall A, Carter SF, Scholl M, Choo ILH, Grimmer T, Redolfi A, Nordberg A, Scheltens P, Drzezga A, Frisoni GB. 2019. Prognostic value of Alzheimer's biomarkers in mild cognitive impairment: the effect of age at onset. Journal of neurology 266:2535-2545. DOI: 10.1007/s00415-01909441-7.

Amjad H, Roth DL, Sheehan OC, Lyketsos CG, Wolff JL, Samus QM. 2018. Underdiagnosis of Dementia: an Observational Study of Patterns in Diagnosis and Awareness in US Older Adults. Journal of general internal medicine 33:1131-1138. DOI: $10.1007 / \mathrm{s} 11606-018-4377-y$.

Andreasen N, Minthon L, Clarberg A, Davidsson P, Gottfries J, Vanmechelen E, Vanderstichele H, Winblad B, Blennow K. 1999. Sensitivity, specificity, and stability of CSF-tau in AD in a community-based patient sample. Neurology 53:1488-1494. DOI: $10.1212 /$ wnl.53.7.1488.

Bouallègue F Ben, Mariano-Goulart D, Payoux P. 2017. Comparison of CSF markers and semi-quantitative amyloid PET in Alzheimer's disease diagnosis and in cognitive impairment prognosis using the ADNI-2 database. Alzheimer's Research and Therapy 9. DOI: 10.1186/s13195-017-0260-z.

Bruun M, Frederiksen KS, Rhodius-Meester HFM, Baroni M, Gjerum L, Koikkalainen J, Urhemaa T, Tolonen A, van Gils M, Tong T, Guerrero R, Rueckert D, Dyremose N, Andersen BB, Simonsen AH, Lemstra A, Hallikainen M, Kurl S, Herukka S-K, Remes AM, Waldemar G, Soininen H, Mecocci P, van der Flier WM, Lötjönen J, Hasselbalch SG. 2019. Impact of a Clinical Decision Support Tool on Dementia Diagnostics in Memory Clinics: The PredictND Validation Study. Current Alzheimer Research 16:91-101. DOI: 10.2174/1567205016666190103152425.

Chetelat G, Eustache F, Viader F, De La Sayette V, Pelerin A, Mezenge F, Hannequin D, Dupuy B, Baron J-C, Desgranges B. 2005. FDG-PET measurement is more accurate than neuropsychological assessments to predict global cognitive deterioration in patients with mild cognitive impairment. Neurocase 11:14-25. DOI: 10.1080/13554790490896938.

Dickerson BC, Wolk DA. 2013. Biomarker-based prediction of progression in $\mathrm{MCl}$ : Comparison of AD signature and hippocampal volume with spinal fluid amyloid- $\beta$ and tau. Frontiers in Aging Neuroscience 5. DOI: 10.3389/fnagi.2013.00055.

Fellgiebel A, Scheurich A, Bartenstein P, Müller MJ. 2007. FDG-PET and CSF phospho-tau for prediction of cognitive decline in mild cognitive impairment. 
610

611

612

613

614

615

616

617

618

619

620

621

622

623

624

625

626

627

628

629

630

631

632

633

634

635

636

637

638

639

640

641

642

643

644

645

646

647

648

649

650

651

652

653

654

655

Psychiatry Research - Neuroimaging 155:167-171. DOI:

10.1016/j.pscychresns.2006.12.002.

Folstein MF, Folstein SE, McHugh PR. 1975. "Mini-mental state". A practical method for grading the cognitive state of patients for the clinician. Journal of Psychiatric Research 12:189-198. DOI: 10.1016/0022-3956(75)90026-6.

Gallivanone F, Della Rosa PA, Castiglioni I. 2016. Statistical Voxel-Based Methods and [18F]FDG PET Brain Imaging: Frontiers for the Diagnosis of AD. Current Alzheimer research 13:682-694.

Geneva: World Health, Organization. 2017. Global action plan on the public health response to dementia 2017-2025 Licence: CC BY-NC-SA 3.0 IGO.

Hansson O, Seibyl J, Stomrud E, Zetterberg H, Trojanowski JQ, Bittner T, Lifke V, Corradini V, Eichenlaub U, Batrla R, Buck K, Zink K, Rabe C, Blennow K, Shaw LM. 2018. CSF biomarkers of Alzheimer's disease concord with amyloid-beta PET and predict clinical progression: A study of fully automated immunoassays in BioFINDER and ADNI cohorts. Alzheimer's \& dementia : the journal of the Alzheimer's Association 14:1470-1481. DOI: 10.1016/j.jalz.2018.01.010.

Harper L, Bouwman F, Burton EJ, Barkhof F, Scheltens P, O'Brien JT, Fox NC, Ridgway GR, Schott JM. 2017. Patterns of atrophy in pathologically confirmed dementias: a voxelwise analysis. Journal of neurology, neurosurgery, and psychiatry 88:908-916. DOI: 10.1136/jnnp-2016-314978.

Herukka SK, Simonsen AH, Andreasen N, Baldeiras I, Bjerke M, Blennow K, Engelborghs S, Frisoni GB, Gabryelewicz T, Galluzzi S, Handels R, Kramberger MG, Kulczyńska A, Molinuevo JL, Mroczko B, Nordberg A, Oliveira CR, Otto M, Rinne JO, Rot U, Saka E, Soininen H, Struyfs H, Suardi S, Visser PJ, Winblad B, Zetterberg H, Waldemar G. 2017. Recommendations for cerebrospinal fluid Alzheimer's disease biomarkers in the diagnostic evaluation of mild cognitive impairment. Alzheimer's and Dementia 13:285-295. DOI:

10.1016/j.jalz.2016.09.009.

Hughes CP, Berg L, Danziger W, Coben LA, Martin RL. 1982. A New Clinical Scale for the Staging of Dementia. British Journal of Psychiatry 140:566-572. DOI: 10.1192/bjp.140.6.566.

Jack CR, Knopman DS, Jagust WJ, Petersen RC, Weiner MW, Aisen PS, Shaw LM, Vemuri P, Wiste HJ, Weigand SD, Lesnick TG, Pankratz VS, Donohue MC, Trojanowski JQ. 2013. Updated hypothetical model of dynamic biomarkers. Lancet neurology 12:207-16. DOI: 10.1016/S1474-4422(12)70291-0.

Kato T, Inui Y, Nakamura A, Ito K. 2016. Brain fluorodeoxyglucose (FDG) PET in dementia. Ageing Research Reviews 30:73-84. DOI: 10.1016/j.arr.2016.02.003.

Kester MI, Van Der Vlies AE, Blankenstein MA, Pijnenburg YAL, Van Elk EJ, Scheltens $P$, Van Der Flier WM. 2009. CSF biomarkers predict rate of cognitive decline in Alzheimer disease. Neurology 73:1353-1358. DOI:

10.1212/WNL.0b013e3181bd8271.

Koikkalainen J, Rhodius-Meester H, Tolonen A, Barkhof F, Tijms B, Lemstra AW, Tong T, Guerrero R, Schuh A, Ledig C, Rueckert D, Soininen H, Remes AM, Waldemar G, Hasselbalch S, Mecocci P, van der Flier W, Lötjönen J. 2016. Differential diagnosis of neurodegenerative diseases using structural MRI data. Neurolmage: Clinical 11:435-449. DOI: 10.1016/J.NICL.2016.02.019. 
656

657

658

659

660

661

662

663

664

665

666

667

668

669

670

671

672

673

674

675

676

677

678

679

680

681

682

683

684

685

686

687

688

689

690

691

692

693

694

695

696

697

698

699

700

701

Landau SM, Harvey D, Madison CM, Reiman EM, Foster NL, Aisen PS, Petersen RC, Shaw LM, Trojanowski JQ, Jack CR, Weiner MW, Jagust WJ. 2010. Comparing predictors of conversion and decline in mild cognitive impairment. Neurology 75:230-238. DOI: 10.1212/WNL.0b013e3181e8e8b8.

Liguori C, Olivola E, Pierantozzi M, Cerroni R, Galati S, Saviozzi V, Mercuri NB, Stefani A. 2017. Cerebrospinal-fluid Alzheimer's Disease Biomarkers and Blood-Brain Barrier Integrity in a Natural Population of Cognitive Intact Parkinson's Disease Patients. CNS \& neurological disorders drug targets 16:339-345. DOI: 10.2174/1871527316666161205123123.

Masters CL, Bateman R, Blennow K, Rowe CC, Sperling RA, Cummings JL. 2015. Alzheimer's disease. Nature Reviews Disease Primers 1:15056. DOI:

10.1038/nrdp.2015.56.

McGhee DJM, Counsell CE, Wright DE, Thompson PA, Ritchie CW, Zajicek JP. 2014. A Systematic Review of Biomarkers for Disease Progression in Alzheimer's Disease. PLOS ONE 9:e88854. DOI: 10.1371/journal.pone.0088854.

McKhann GM, Knopman DS, Chertkow H, Hyman BT, Jack CR, Kawas CH, Klunk WE, Koroshetz WJ, Manly JJ, Mayeux R, Mohs RC, Morris JC, Rossor MN, Scheltens P, Carrillo MC, Thies B, Weintraub S, Phelps CH. 2011. The diagnosis of dementia due to Alzheimer's disease: Recommendations from the National Institute on Aging-Alzheimer's Association workgroups on diagnostic guidelines for Alzheimer's disease. Alzheimer's and Dementia 7:263-269. DOI: 10.1016/j.jalz.2011.03.005.

Meyer P-F, Binette AP, Gonneaud J, Breitner JCS, Villeneuve S. 2020. Characterization of Alzheimer Disease Biomarker Discrepancies Using Cerebrospinal Fluid Phosphorylated Tau and AV1451 Positron Emission Tomography. JAMA Neurology. DOI: 10.1001/jamaneurol.2019.4749.

Mielke R, Herholz K, Grond M, Kessler J, Heiss WD. 1994. Clinical deterioration in probable Alzheimer's disease correlates with progressive metabolic impairment of association areas. Dementia (Basel, Switzerland) 5:36-41.

Mueller C, Ballard C, Corbett A, Aarsland D. 2017. The prognosis of dementia with Lewy bodies. The Lancet Neurology 16:390-398. DOI: 10.1016/S14744422(17)30074-1.

Nestor PJ. 2017. Dementia, Fifth Edition. CRC Press. DOI: 10.1201/9781315381572.

Nestor SM, Rupsingh R, Borrie M, Smith M, Accomazzi V, Wells JL, Fogarty J, Bartha R. 2008. Ventricular enlargement as a possible measure of Alzheimer's disease progression validated using the Alzheimer's disease neuroimaging initiative database. Brain : a journal of neurology 131:2443-2454. DOI: 10.1093/brain/awn146.

Ottoy J, Niemantsverdriet E, Verhaeghe J, De Roeck E, Struyfs H, Somers C, Wyffels L, Ceyssens S, Van Mossevelde S, Van den Bossche T, Van Broeckhoven C, Ribbens A, Bjerke M, Stroobants S, Engelborghs S, Staelens S. 2019. Association of short-term cognitive decline and MCl-to-AD dementia conversion with CSF, MRI, amyloid- and (18)F-FDG-PET imaging. Neurolmage. Clinical 22:101771. DOI: 10.1016/j.nicl.2019.101771.

Perani D, Cerami C, Caminiti S, Santangelo R, Coppi E, Ferrari L, Pinto P, Passerini G, Falini A, lannaccone S, Cappa S, Comi G, Gianolli L, Magnani G. 2016. Crossvalidation of biomarkers for the early differential diagnosis and prognosis of 
702

703

704

705

706

707

708

709

710

711

712

713

714

715

716

717

718

719

720

721

722

723

724

725

726

727

728

729

730

731

732

733

734

735 dementia in a clinical setting. European Journal of Nuclear Medicine \& Molecular Imaging 43:499-508.

Prince M, Bryce R, Albanese E, Wimo A, Ribeiro W, Ferri CP. 2013. The global prevalence of dementia: A systematic review and metaanalysis. Alzheimer's and Dementia 9:63-75.e2. DOI: 10.1016/j.jalz.2012.11.007.

R Core Team, R: A Language and Environment for Statistical Computing. 2016.

Shivamurthy VKN, Tahari AK, Marcus C, Subramaniam RM. 2015. Brain FDG PET and the Diagnosis of Dementia. American Journal of Roentgenology 204:W76-W85. DOI: 10.2214/AJR.13.12363.

Spillantini MG, Goedert M. 2013. Tau pathology and neurodegeneration. The Lancet Neurology 12:609-622. DOI: 10.1016/S1474-4422(13)70090-5.

Varrone A, Asenbaum S, Vander Borght T, Booij J, Nobili F, Nagren K, Darcourt J, Kapucu OL, Tatsch K, Bartenstein P, Van Laere K. 2009. EANM procedure guidelines for PET brain imaging using [18F]FDG, version 2. European journal of nuclear medicine and molecular imaging 36:2103-2110. DOI: 10.1007/s00259-0091264-0.

Vemuri P, Wiste HJ, Weigand SD, Knopman DS, Trojanowski JQ, Shaw LM, Bernstein MA, Aisen PS, Weiner M, Petersen RC, Jack CRJ. 2010. Serial MRI and CSF biomarkers in normal aging, $\mathrm{MCl}$, and AD. Neurology 75:143-151. DOI: 10.1212/WNL.0b013e3181e7ca82.

Walhovd KB, Fjell AM, Brewer J, McEvoy LK, Fennema-Notestine C, Hagler DJ, Jennings RG, Karow D, Dale AM. 2010a. Combining MR imaging, positronemission tomography, and CSF biomarkers in the diagnosis and prognosis of Alzheimer disease. American Journal of Neuroradiology 31:347-354. DOI: 10.3174/ajnr.A1809.

Walhovd KB, Fjell AM, Dale AM, McEvoy LK, Brewer J, Karow DS, Salmon DP, Fennema-Notestine C. 2010b. Multi-modal imaging predicts memory performance in normal aging and cognitive decline. Neurobiology of Aging 31:1107-1121. DOI: 10.1016/j.neurobiolaging.2008.08.013.

Zetterberg H, Hietala MA, Jonsson M, Andreasen N, Styrud E, Karlsson I, Edman A, Popa C, Rasulzada A, Wahlund L-O, Mehta PD, Rosengren L, Blennow K, Wallin A. 2006. Neurochemical aftermath of amateur boxing. Archives of neurology 63:1277-1280. DOI: 10.1001/archneur.63.9.1277. 
Figure 1

Correlogram showing Spearman correlations of markers of neurodegeneration.

For subset of cohort with CSF-total tau, $\mathrm{N}=76$. NS $=$ not significant.

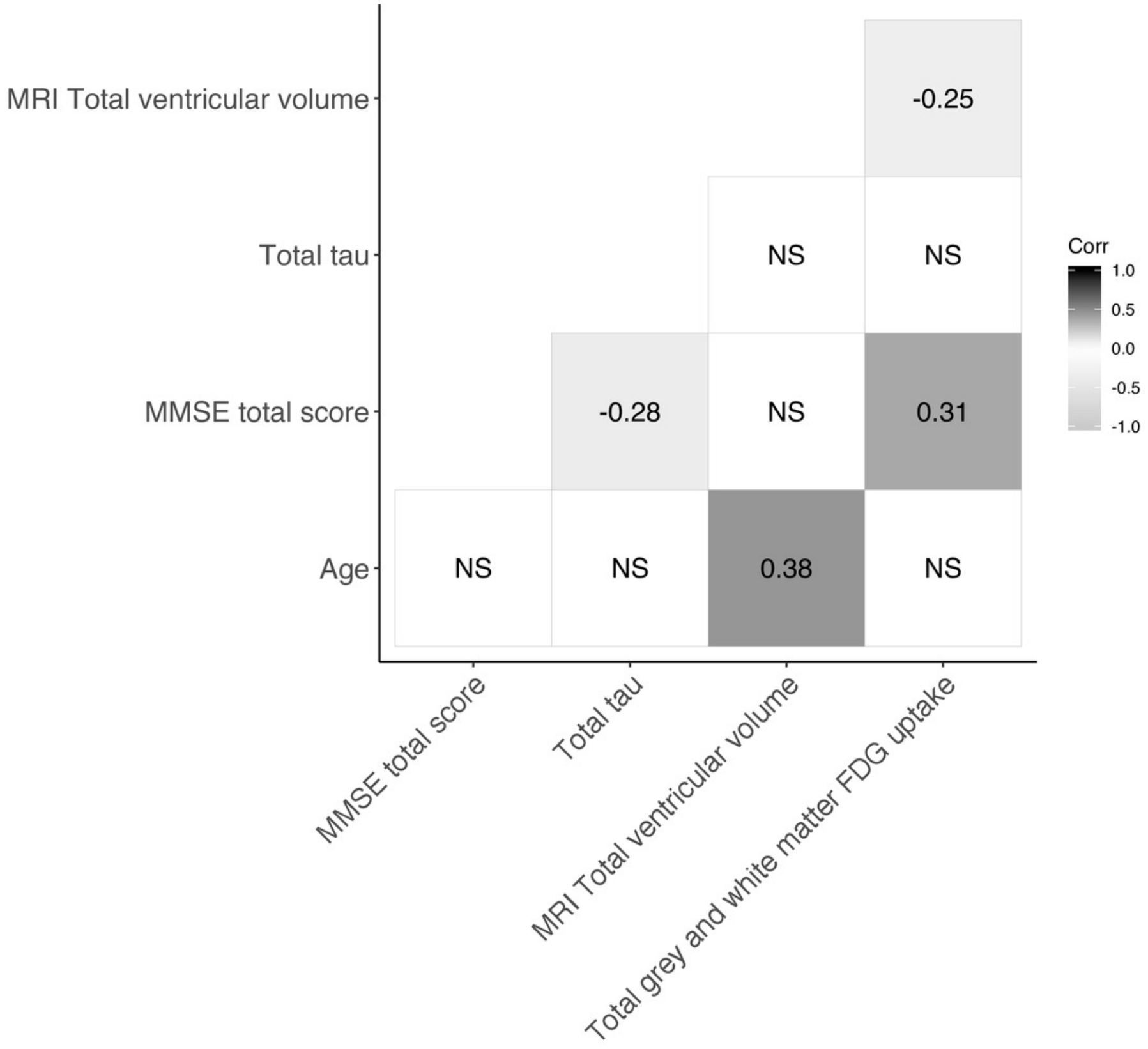


Table $\mathbf{1}$ (on next page)

Baseline characteristics. 


\begin{tabular}{|c|c|c|c|c|}
\hline Variable & Progression $(\mathrm{N}=50)$ & Stable (N=99) & Total $(\mathrm{N}=149)$ & P-value \\
\hline Gender & & & & $0.687^{1}$ \\
\hline Female & $27(54.0 \%)$ & $50(50.5 \%)$ & $77(51.7 \%)$ & \\
\hline Male & $23(46.0 \%)$ & $49(49.5 \%)$ & $72(48.3 \%)$ & \\
\hline Age, years & & & & $0.003^{2}$ \\
\hline Mean (SD) & $73.6(9.2)$ & $68.6(9.7)$ & $70.3(9.8)$ & \\
\hline $\begin{array}{l}\text { Mini-Mental State Examination total } \\
\text { score }\end{array}$ & & & & $<0.001^{3}$ \\
\hline Median (range) & $26(19-30)$ & $29(18-30)$ & $28(18-30)$ & \\
\hline Consensus conference diagnosis & & & & $<0.001^{4}$ \\
\hline Dementia & $42(84.0 \%)$ & $39(39.4 \%)$ & $81(54.4 \%)$ & \\
\hline Mild cognitive impairment (MCI) & $7(14.0 \%)$ & $26(26.3 \%)$ & $33(22.1 \%)$ & \\
\hline Subjective cognitive decline & $1(2.0 \%)$ & $34(34.3 \%)$ & $35(23.5 \%)$ & \\
\hline $\begin{array}{l}\text { Dementia etiology (consensus } \\
\text { conference diagnosis) }\end{array}$ & & & & $0.308^{4}$ \\
\hline Alzheimer's dementia & $28(66.7 \%)$ & $19(48.7 \%)$ & $47(58.0 \%)$ & \\
\hline Atypical Alzheimer's dementia & $1(2.4 \%)$ & $2(5.1 \%)$ & $3(3.7 \%)$ & \\
\hline $\begin{array}{l}\text { Atypical parkinsonism + Parkinson's } \\
\text { disease with dementia }\end{array}$ & $2(4.8 \%)$ & $1(2.6 \%)$ & $3(3.7 \%)$ & \\
\hline Alcohol-related dementia & $0(0.0 \%)$ & $1(2.6 \%)$ & $1(1.2 \%)$ & \\
\hline Frontotemporal dementia & $2(4.8 \%)$ & $1(2.6 \%)$ & $3(3.7 \%)$ & \\
\hline Lewy body dementia & $0(0.0 \%)$ & $4(10.3 \%)$ & $4(4.9 \%)$ & \\
\hline Mixed dementia & $1(2.4 \%)$ & $3(7.7 \%)$ & $4(4.9 \%)$ & \\
\hline Normal pressure hydrocephalus & $0(0.0 \%)$ & $1(2.6 \%)$ & $1(1.2 \%)$ & \\
\hline Other & $2(4.8 \%)$ & $3(7.7 \%)$ & $5(6.2 \%)$ & \\
\hline Vascular dementia & $6(14.3 \%)$ & $4(10.3 \%)$ & $10(12.3 \%)$ & \\
\hline CSF-total tau (ng/L) & & & & $0.259^{3}$ \\
\hline Median (range), $\mathrm{n}=76$ & $370(126-1200)$ & $347(36-993)$ & $360(36-1200)$ & \\
\hline $\mathrm{N}(\%)$ with elevated $(>400 \mathrm{ng} / \mathrm{L})$ tau & $21(42.9 \%)$ & $13(48.1 \%)$ & $34(44.7 \%)$ & \\
\hline MRI total ventricular volume $\left(\mathrm{mm}^{3}\right)$ & & & & $0.007^{3}$ \\
\hline Median (range) & $64772(24318-239803)$ & $50402(14760-193975)$ & $57363(14760-239803)$ & \\
\hline $\begin{array}{l}\text { [ }{ }^{18} \text { F]FDG-PET Cerebral gray and white } \\
\text { matter total uptake (SUVr normalized to } \\
\text { cerebellum) }\end{array}$ & & & & $<0.001^{2}$ \\
\hline Mean (SD) & $1.050(0.081)$ & $1.113(0.112)$ & $1.092(0.106)$ & \\
\hline
\end{tabular}


Table 2 (on next page)

Markers of neurodegeneration and their relation to clinical progression. 


\begin{tabular}{|c|c|c|c|c|c|}
\hline Variable & Levels & Stable & Progression & $\begin{array}{l}\text { Odds ratio } \\
\text { (univariable) }\end{array}$ & $\begin{array}{c}\text { Odds ratio } \\
\text { (multivariable) }\end{array}$ \\
\hline \multicolumn{6}{|l|}{ Model 1} \\
\hline Age & Mean (SD) & $68.7(8.9)^{+}$ & $71.1(9.9)^{\S}$ & $\begin{array}{r}1.03(0.98-1.09 \\
p=0.272)\end{array}$ & $\begin{array}{r}1.02(0.96-1.08 \\
p=0.497)\end{array}$ \\
\hline \multirow[t]{2}{*}{ Gender } & Female & $24(49.0)$ & $13(48.1)$ & - & - \\
\hline & Male & $25(51.0)$ & 14 (51.9) & $\begin{array}{r}1.03(0.40-2.65 \\
p=0.945)\end{array}$ & $\begin{array}{r}1.01(0.38-2.70 \\
p=0.983)\end{array}$ \\
\hline \multirow{4}{*}{$\begin{array}{l}\text { Abnormal markers (MRI, } \\
{\left[{ }^{18} \mathrm{~F}\right] \text { FDG-PET and tau) }}\end{array}$} & 0 & $16(32.7)$ & $4(14.8)$ & - & - \\
\hline & 1 & $14(28.6)$ & $9(33.3)$ & $\begin{array}{r}2.57(0.65-10.21 \\
p=0.179)\end{array}$ & $\begin{array}{r}2.38(0.59-9.66 \\
p=0.225)\end{array}$ \\
\hline & 2 & $16(32.7)$ & $11(40.7)$ & $\begin{array}{r}2.75(0.72-10.48 \\
p=0.138)\end{array}$ & $\begin{array}{r}2.40(0.59-9.71 \\
p=0.221)\end{array}$ \\
\hline & 3 & $3(6.1)$ & $3(11.1)$ & $\begin{array}{r}4.00(0.58-27.82 \\
p=0.161)\end{array}$ & $\begin{array}{r}3.66(0.51-26.36 \\
p=0.198)\end{array}$ \\
\hline \multicolumn{6}{|l|}{ Model 2} \\
\hline Age & Mean (SD) & $68.6(9.7)$ & $73.6(9.2)$ & $\begin{array}{r}1.06(1.02-1.10 \\
p=0.004)\end{array}$ & $\begin{array}{r}1.04(0.99-1.08 \\
p=0.103)\end{array}$ \\
\hline \multirow[t]{2}{*}{ Gender } & Female & $50(50.5)$ & $27(54.0)$ & - & - \\
\hline & Male & $49(49.5)$ & $23(46.0)$ & $\begin{array}{r}0.87(0.44-1.72 \\
p=0.687)\end{array}$ & $\begin{array}{r}0.78(0.37-1.65 \\
p=0.517)\end{array}$ \\
\hline \multirow{3}{*}{$\begin{array}{l}\text { Abnormal markers (MRI, } \\
{\left[{ }^{18} \mathrm{~F}\right] \text { FDG-PET) }}\end{array}$} & 0 & $42(42.4)$ & $8(16.0)$ & - & - \\
\hline & 1 & $35(35.4)$ & $23(46.0)$ & $\begin{array}{r}3.45(1.37-8.67 \\
p=0.008)\end{array}$ & $\begin{array}{r}2.68(1.01-7.12 \\
p=0.048)\end{array}$ \\
\hline & 2 & $22(22.2)$ & $19(38.0)$ & $\begin{array}{r}4.53(1.71-12.01 \\
p=0.002)\end{array}$ & $\begin{array}{r}3.45(1.16-10.28 \\
p=0.026)\end{array}$ \\
\hline
\end{tabular}




\section{Table $\mathbf{3}$ (on next page)}

Atrophy/hypometabolism patterns and their relation to clinical progression. 


\begin{tabular}{|c|c|c|c|c|c|}
\hline Variable & Level & Stable & Progressed & $\begin{array}{c}\text { Odds ratio } \\
\text { (univariable) }\end{array}$ & $\begin{array}{c}\text { Odds ratio } \\
\text { (multivariable) }\end{array}$ \\
\hline Age & Mean (SD) & $\begin{array}{l}68.6 \\
(9.7)^{\neq}\end{array}$ & $73.6(9.2)^{\S}$ & $\begin{array}{r}1.06(1.02-1.10 \\
p=0.004)\end{array}$ & $\begin{array}{l}1.04(1.00-1.09 \\
p=0.045)\end{array}$ \\
\hline \multirow[t]{2}{*}{ Sex } & Female & $50(50.5)$ & $27(54.0)$ & - & - \\
\hline & Male & 49 (49.5) & $23(46.0)$ & $\begin{array}{r}0.87(0.44-1.72 \\
p=0.687)\end{array}$ & $\begin{array}{l}1.48(0.59-3.71 \\
p=0.406)\end{array}$ \\
\hline \multirow{2}{*}{$\begin{array}{l}\text { +Atrophy, - } \\
\text { Hypometabolism* }\end{array}$} & 0-1 affected lobes & $58(58.6)$ & $32(64.0)$ & - & - \\
\hline & $\begin{array}{l}2 \text { or more affected } \\
\text { lobes }\end{array}$ & $41(41.4)$ & $18(36.0)$ & $\begin{array}{r}0.80(0.39-1.61 \\
p=0.524)\end{array}$ & $\begin{array}{l}1.15(0.50-2.65 \\
p=0.742)\end{array}$ \\
\hline \multirow{2}{*}{$\begin{array}{l}\text {-Atrophy, } \\
+ \text { +Hypometabolism }\end{array}$} & 0-1 affected lobes & $67(67.7)$ & $32(64.0)$ & - & - \\
\hline & $\begin{array}{l}2 \text { or more affected } \\
\text { lobes }\end{array}$ & $32(32.3)$ & $18(36.0)$ & $\begin{array}{r}1.18(0.58-2.41 \\
p=0.654)\end{array}$ & $\begin{array}{l}1.14(0.45-2.90, \\
p=0.778)\end{array}$ \\
\hline \multirow{2}{*}{$\begin{array}{l}\text { +Atrophy, } \\
\text { +Hypometabolism }\end{array}$} & 0-1 affected lobes & $69(69.7)$ & $17(34.0)$ & - & - \\
\hline & $\begin{array}{l}2 \text { or more affected } \\
\text { lobes }\end{array}$ & $30(30.3)$ & $33(66.0)$ & $\begin{array}{r}4.46(2.16-9.22 \\
p<0.001)\end{array}$ & $\begin{array}{l}4.33(1.90-9.86 \\
p<0.001)\end{array}$ \\
\hline
\end{tabular}


Table 4 (on next page)

Isolated atrophy/hypometabolism patterns and their relation to clinical progression. 


\begin{tabular}{|c|c|c|c|c|c|}
\hline Variable & Level & Stable & Progressed & $\begin{array}{l}\text { Odds ratio } \\
\text { (univariable) }\end{array}$ & $\begin{array}{c}\text { Odds ratio } \\
\text { (multivariable) }\end{array}$ \\
\hline Age & Mean (SD) & $\begin{array}{l}68.6 \\
(9.7)^{\ddagger}\end{array}$ & $73.6(9.2)^{\S}$ & $\begin{array}{r}1.06(1.02-1.10 \\
p=0.004)\end{array}$ & $\begin{array}{l}1.05(1.00-1.10 \\
p=0.064)\end{array}$ \\
\hline \multirow[t]{2}{*}{ Sex } & Female & $\begin{array}{l}50 \\
(50.5)\end{array}$ & $27(54.0)$ & - & - \\
\hline & Male & $\begin{array}{l}49 \\
(49.5)\end{array}$ & $23(46.0)$ & $\begin{array}{r}0.87(0.44-1.72 \\
p=0.687)\end{array}$ & $\begin{array}{l}1.21(0.38-3.87 \\
p=0.751)\end{array}$ \\
\hline \multirow[t]{2}{*}{ +Atrophy, -Hypometabolism* } & $0-1$ affected lobes & $\begin{array}{l}58 \\
(58.6)\end{array}$ & $32(64.0)$ & - & - \\
\hline & 2 or more affected lobes & $\begin{array}{l}41 \\
(41.4)\end{array}$ & $18(36.0)$ & $\begin{array}{r}0.80(0.39-1.61 \\
p=0.524)\end{array}$ & $\begin{array}{l}1.96(0.42-9.19 \\
p=0.392)\end{array}$ \\
\hline \multirow[t]{2}{*}{-Atrophy, +Hypometabolism } & $0-1$ affected lobes & $\begin{array}{l}67 \\
(67.7)\end{array}$ & $32(64.0)$ & - & - \\
\hline & 2 or more affected lobes & $\begin{array}{l}32 \\
(32.3)\end{array}$ & $18(36.0)$ & $\begin{array}{r}1.18(0.58-2.41 \\
p=0.654)\end{array}$ & $\begin{array}{l}0.68(0.16-2.99 \\
p=0.612)\end{array}$ \\
\hline \multirow[t]{2}{*}{ +Atrophy, +Hypometabolism } & $0-1$ affected lobes & $\begin{array}{l}69 \\
(69.7)\end{array}$ & $17(34.0)$ & - & - \\
\hline & 2 or more affected lobes & $\begin{array}{l}30 \\
(30.3)\end{array}$ & $33(66.0)$ & $\begin{array}{r}4.46(2.16-9.22 \\
p<0.001)\end{array}$ & $\begin{array}{l}7.60(1.26-46.01 \\
p=0.027)\end{array}$ \\
\hline \multirow[t]{4}{*}{$\begin{array}{l}\text { Frontal isolated } \\
\text { atrophy/hypometabolism }\end{array}$} & No abnormality & $\begin{array}{l}25 \\
(25.3)\end{array}$ & $4(8.0)$ & - & - \\
\hline & $\begin{array}{l}\text { Any congruence and/or non-isolated } \\
\text { atrophy/hypometabolism }^{+}\end{array}$ & $\begin{array}{l}20 \\
(20.2)\end{array}$ & $25(50.0)$ & $\begin{array}{r}7.81(2.33-26.15 \\
p=0.001)\end{array}$ & $\begin{array}{l}2.60(0.36-18.77 \\
p=0.344)\end{array}$ \\
\hline & Isolated hypometabolism & $\begin{array}{l}23 \\
(23.2)\end{array}$ & $14(28.0)$ & $\begin{array}{r}3.80(1.09-13.24 \\
p=0.036)\end{array}$ & $\begin{array}{l}2.54(0.52-12.48 \\
p=0.252)\end{array}$ \\
\hline & Isolated atrophy & $\begin{array}{l}31 \\
(31.3)\end{array}$ & $7(14.0)$ & $\begin{array}{r}1.41(0.37-5.37 \\
p=0.613)\end{array}$ & $\begin{array}{l}0.87(0.12-6.46 \\
p=0.892)\end{array}$ \\
\hline \multirow[t]{4}{*}{$\begin{array}{l}\text { Temporal isolated } \\
\text { atrophy/hypometabolism }\end{array}$} & No abnormality & $\begin{array}{l}28 \\
(28.3)\end{array}$ & $6(12.0)$ & - & - \\
\hline & $\begin{array}{l}\text { Any congruence and/or non-isolated } \\
\text { atrophy/hypometabolism }\end{array}$ & $\begin{array}{l}28 \\
(28.3)\end{array}$ & $30(60.0)$ & $\begin{array}{r}5.00(1.80-13.88 \\
p=0.002)\end{array}$ & $\begin{array}{l}2.97(0.42-21.04 \\
p=0.276)\end{array}$ \\
\hline & Isolated hypometabolism & $\begin{array}{l}21 \\
(21.2)\end{array}$ & $8(16.0)$ & $\begin{array}{r}1.78(0.54-5.90 \\
p=0.347)\end{array}$ & $\begin{array}{l}2.00(0.26-15.51 \\
p=0.508)\end{array}$ \\
\hline & Isolated atrophy & $\begin{array}{l}22 \\
(22.2)\end{array}$ & $6(12.0)$ & $\begin{array}{r}1.27(0.36-4.50 \\
p=0.708)\end{array}$ & $\begin{array}{l}2.43(0.35-16.91 \\
p=0.370)\end{array}$ \\
\hline \multirow[t]{4}{*}{$\begin{array}{l}\text { Parietal isolated } \\
\text { atrophy/hypometabolism }\end{array}$} & No abnormality & $\begin{array}{l}26 \\
(26.3)\end{array}$ & $7(14.0)$ & - & - \\
\hline & $\begin{array}{l}\text { Any congruence and/or non-isolated } \\
\text { atrophy/hypometabolism }\end{array}$ & $\begin{array}{l}28 \\
(28.3)\end{array}$ & $27(54.0)$ & $\begin{array}{r}3.58(1.33-9.62 \\
p=0.011)\end{array}$ & $\begin{array}{l}0.96(0.16-5.91 \\
p=0.967)\end{array}$ \\
\hline & Isolated hypometabolism & $\begin{array}{l}20 \\
(20.2)\end{array}$ & $10(20.0)$ & $\begin{array}{r}1.86(0.60-5.74 \\
p=0.282)\end{array}$ & $\begin{array}{l}2.06(0.33-12.99 \\
p=0.442)\end{array}$ \\
\hline & Isolated atrophy & $\begin{array}{l}25 \\
(25.3)\end{array}$ & $6(12.0)$ & $\begin{array}{r}0.89(0.26-3.02 \\
p=0.854)\end{array}$ & $\begin{array}{l}0.76(0.11-5.19 \\
p=0.776)\end{array}$ \\
\hline \multirow[t]{4}{*}{$\begin{array}{l}\text { Occipital isolated } \\
\text { atrophy/hypometabolism }\end{array}$} & No abnormality & $\begin{array}{l}17 \\
(17.2)\end{array}$ & $9(18.0)$ & - & - \\
\hline & $\begin{array}{l}\text { Any congruence and/or non-isolated } \\
\text { atrophy/hypometabolism }\end{array}$ & $\begin{array}{l}33 \\
(33.3)\end{array}$ & $21(42.0)$ & $\begin{array}{r}1.20(0.45-3.19 \\
p=0.712)\end{array}$ & $\begin{array}{l}0.06(0.01-0.46 \\
p=0.006)\end{array}$ \\
\hline & Isolated hypometabolism & $\begin{array}{l}20 \\
(20.2)\end{array}$ & $10(20.0)$ & $\begin{array}{r}0.94(0.31-2.86 \\
p=0.920)\end{array}$ & $\begin{array}{l}0.29(0.04-1.84 \\
p=0.189)\end{array}$ \\
\hline & Isolated atrophy & $\begin{array}{l}29 \\
(29.3)\end{array}$ & $10(20.0)$ & $\begin{array}{r}0.65(0.22-1.92 \\
p=0.437)\end{array}$ & $\begin{array}{l}0.25(0.04-1.64 \\
p=0.149)\end{array}$ \\
\hline
\end{tabular}

